\title{
Future study for the urinary histidine adduct derived from pyrrolizidine alkaloids is warranted
}

\author{
Lin Zhu ${ }^{1} \cdot$ Chunyuan Zhang ${ }^{1} \cdot$ Jiang $\mathrm{Ma}^{1} \cdot$ Yisheng $\mathrm{He}^{1} \cdot \mathrm{Ge} \operatorname{Lin}^{1}$
}

Received: 13 September 2021 / Accepted: 16 September 2021 / Published online: 24 September 2021

(c) The Author(s), under exclusive licence to Springer-Verlag GmbH Germany, part of Springer Nature 2021

We received comments from a reader on our recently published research article entitled "Developing urinary pyrroleamino acid adducts as non-invasive biomarkers for identifying pyrrolizidine alkaloids-induced liver injury in human (https://doi.org/10.1007/s00204-021-03129-6)". In this study, we detected pyrrole-9-histidine in urine of rats and patients exposed to pyrrolizidine alkaloids and identified the structure by comparison of its HPLC retention time and mass spectrum with those of a synthetic standard with the pyrrole moiety attached to the histidine $N$-terminal. However, since this urinary pyrrole-9-histidine is likely formed from degradation of pyrrole-protein adducts in the body, this reader suggested that based on protein biochemistry, the structure of pyrrole-9-histidine that we identified in the urine should be favorably the one with the pyrrole moiety attached to the $\mathrm{N}$ atom in the imidazole of histidine. We agree with this reader's suggestion. According to the experimental results obtained so far, we cannot unequivocally determine the structure of this urinary pyrrole-9-histidine, although the pyrrole-9-histidine isomer with its pyrrole moiety attached to the imidazole is favorable to the N-terminal of histidine isomer. Future study is warranted to identify the structure of this urinary pyrrole-9-histidine.

Publisher's Note Springer Nature remains neutral with regard to jurisdictional claims in published maps and institutional affiliations.
Ge Lin

linge@cuhk.edu.hk

1 School of Biomedical Sciences, Faculty of Medicine, The Chinese University of Hong Kong, Hong Kong, Hong Kong SAR 